\title{
Review of the Reuse Possibilities Concerning Ash Residues from Thermal Process in a Medium-Sized Urban System in Northern Italy
}

\author{
Ahmad Assi ${ }^{1}$, Fabjola Bilo ${ }^{1}$, Alessandra Zanoletti ${ }^{1}$, Jessica Ponti ${ }^{2}$, Andrea Valsesia ${ }^{2} \mathbb{}$, \\ Rita La Spina ${ }^{2}$, Laura E. Depero ${ }^{1}$ and Elza Bontempi ${ }^{1, *} \mathbb{D}$ \\ 1 INSTM and Chemistry for Technologies Laboratory, Department of Mechanical and Industrial Engineering, \\ University of Brescia, 25123 Brescia, Italy; a.assi@unibs.it (A.A.); fabjola.bilo@unibs.it (F.B.); \\ alessandra.zanoletti@unibs.it (A.Z.); laura.depero@unibs.it (L.E.D.) \\ 2 European Commission, Joint Research Centre (JRC), 21027 Ispra, Italy; Jessica.PONTI@ec.europa.eu (J.P.); \\ Andrea.VALSESIA@ec.europa.eu (A.V.); Rita.LA-SPINA@ec.europa.eu (R.L.S.) \\ * Correspondence: elza.bontempi@unibs.it
}

Received: 24 April 2020; Accepted: 14 May 2020; Published: 20 May 2020

\begin{abstract}
This review paper reports a detailed characterization of some combustion or incineration residues and by-products produced in a medium-sized city in Northern Italy. The municipal solid waste incineration (MSWI) generates fly ash, which is a toxic waste. Coal fly ash (CFA) and flue gas desulfurization (FGD) derive from the thermoelectric coal plant located in the same city. Along with these ashes, silica fume and rice husk ash are also considered for the stabilization of fly ash based on their amorphous silica content with the aim to convert them into an inert material. The characterization of all the investigated ashes was performed using different techniques: X-ray diffraction, total reflection $\mathrm{X}$-ray fluorescence, scanning electron microscopy, and transmission electron microscopy. The aim of this work is to describe the reuse possibilities that were proposed for these ashes, which were determined also on the basis of their structural properties. Several possible applications of the investigated ashes are proposed, and the most suitable reuse of stabilized fly ash samples seems to be the production of sustainable plastic composites. This paper shows that the reuse of the by-product materials can allow natural resources to be preserved following the principles of a circular economy.
\end{abstract}

Keywords: fly ash; bottom ash; silica fume; coal fly ash; flue gas desulfurization; rice husk ash; stabilized sample; circular economy

\section{Introduction}

Municipal solid waste (MSW) is an abundant waste stream composed of materials and products that should be recycled because of the raw materials it contains. However, this is not always feasible, because MSW includes non-homogenous products with a combination of different materials, such as wood, metals, glass, plastic, etc. [1]. It is known that MSW is composed roughly by organic and inorganic waste in particular, making it very hard to select suitable technologies for its separation. According to the circular economy principles, recycling and prevention are fundamental to increased resource efficiency. However, recycling can require energy and resources that may be higher in comparison to landfill procedures [2].

In Brescia, a medium-sized urban system in Italy, MSW that cannot be separated is incinerated to manage waste in a suitable way and recover energy. The waste-to-energy plant provides a significant contribution to the energy needs of the city. In fact, in addition to producing electricity, it recovers the heat generated and coveys it to the homes of individual users. This is achieved through a district 
heating network of over $670 \mathrm{~km}$. The plant is composed of three interdependent combustion units powered by undifferentiated urban waste and special non-hazardous waste. Moreover, in the same city, a multi-fuel cogeneration thermoelectric plant that uses natural gas and coal to provide district heating and electricity production is also present [3].

As a consequence, in the city, there is a need to properly manage municipal solid waste incineration (MSWI), including fly ash (FA), bottom ash (BA), and coal combustion residues. The MSWI process allows a mass and volume reduction of $70 \%$ and $90 \%$, respectively. Bottom ash represents the $80-90 \%$ of the residue (approximately 1 ton of incinerated MSW produces 1/4 ton BA), and the remainder is fly ash and air pollution control residue [4].

Several activities were done in the last few years (as demonstrated by the published literature studies) devoted to MSW FA and BA characterization. Various application fields have already been proposed, mainly for BA: e.g., metal secondary sources and construction building reuse [5]. Indeed, despite the fact that BA contains a high amount of chloride and metals, such as $\mathrm{Fe}$ and $\mathrm{Cu}[6,7]$, it is considered as non-hazardous waste [8], requiring minimal treatments before its reuse. On the contrary, according to the European Waste Catalogue [9,10], MSWI FA is classified generally as hazardous waste due to its high content of leachable toxic metals (such as $\mathrm{Zn}, \mathrm{Ni}, \mathrm{Cu}, \mathrm{Cr}$, and $\mathrm{Cd}$ ) requiring stabilization, and also because of its landfilling $[5,11]$. Therefore, its reuse is recommended after the application of a suitable stabilization treatment process.

Coal fly ash (CFA), which generally has a composition similar to Portland cement [12] is captured by cyclones in bag-houses and electrostatic precipitators. Flue-gas desulfurization (FGD) residues are produced inside chemical "scrubber" emission control systems that remove sulfur and oxides from power plant flue-gas streams and may attain $24 \%$ of all coal combustion residues [13].

Because coal combustion ashes are generally not considered toxic, they are valuable by-products with a vast array of applications, and so are the most common use of CFA in Portland cement [14]. In this context, it is extremely important to properly characterize these ashes to address the by-products for the most suitable and sustainable applications.

Fly ash recycling is the best strategy for its management, but it can also be seen as one current example of implementing the concept of industrial symbiosis, where waste for one industry can be considered a resource for another one. Indeed, in a natural ecosystem, there are no wastes, but only resources and products. For this aim, research is extremely active in the purpose of reusing all ash typologies as fillers in several applications. Indeed, about 1300 papers have been published (until the end of 2019) on the reuse of ash. Figure 1a shows the number of published papers, also reported per year by the main published source (from the SCOPUS database). It is evident that interest is exponentially increasing. In addition, the interest sector of reuse, which was originally oriented to building materials, is now also devoted to polymer applications, with other limited applications in alternative fields (Figure 1b), such as soil amendment [15,16].
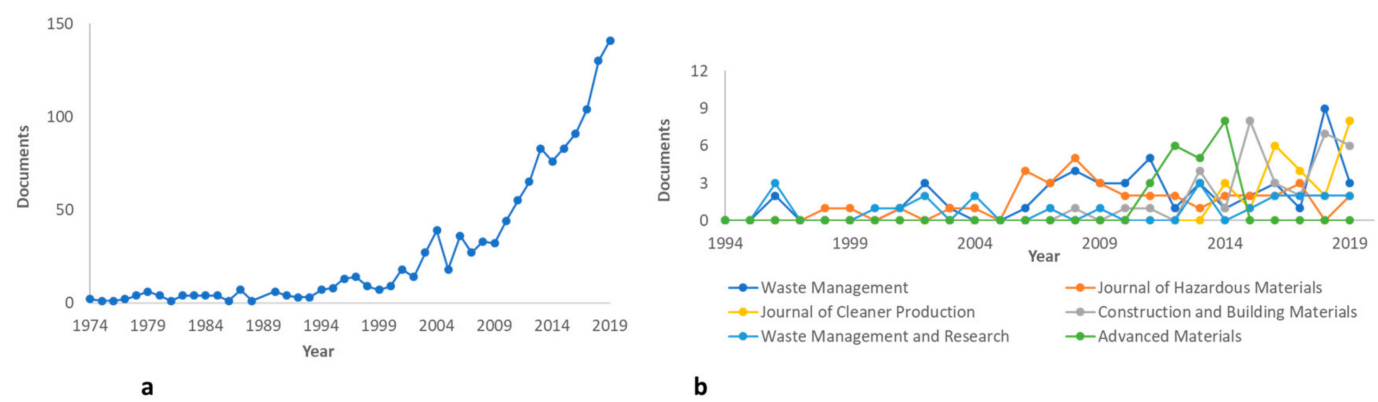

Figure 1. Number of published papers (a) and types of journals publishing the higher number of papers about ash reuses (b).

In particular, in the frame of the research activity made in the last few years [17-20], some of the ashes derived from coal combustion are employed to stabilize fly ash deriving from MSWI in the 
present paper. For this aim, ash also derived from rice husk incineration and silica fume (a silica-rich ash) were used.

This work is devoted to reporting the results of the characterization of ashes that are by-products derived from coal combustion, rice husk combustion, and silica fume. On the basis of their characteristics, their reuse possibilities are also presented. Finally, their contribution to MSWI fly ash stabilization is discussed and the possible use of stabilized material is proposed.

\section{Chemical Characterization of Incineration Residues and Combustion By-Products}

\subsection{Materials}

MSWI residues, MSWI fly ash (FA), and bottom ash (BA), were provided by the incinerator power plant managed by A2A s.p.a. The industrial by-products involved in the MSWI FA stabilization were silica fume (SF, from Metalleghe spa, Italy), rice husk ash (RHA, from Curtiriso s.r.l., Pavia, Italy), coal fly ash (CFA), and flue gas desulfurization (FGD) produced by a coal thermal power plant in Brescia. The coal combustion ash was produced at $1200-170{ }^{\circ} \mathrm{C}$ [21], silica fume at about $2000{ }^{\circ} \mathrm{C}$ [22], MSWI residues at nearly $1000{ }^{\circ} \mathrm{C}$ [23], and rice husk ash at $800^{\circ} \mathrm{C}$ [24].

MilliQ water (Millipore DirectQ-5 purification system) was used for the preparation of stabilized materials.

\subsection{Characterization Techniques}

The minerals and phases identification and amorphous phase quantification and the chemical and detailed imaging of surface morphology of the waste materials were performed by X-ray diffraction (XRD), scanning electron microscopy, X-ray microanalysis (SEM-EDX), and transmission electron microscopy (TEM).

The XRD measurement was performed by a Panalytical X'Pert Pro diffractometer supplied with the $\mathrm{X}^{\prime} \mathrm{Celerator}$ detector and $\mathrm{Cu}$ anode $(\mathrm{CuK} \alpha 1.5406 \AA)$, operating at $40 \mathrm{kV}$ and $40 \mathrm{~mA}$. The spectra samples were collected between 5 and $80^{\circ}(2 \theta)$.

The SEM analysis (FEI NOVA 600 Dual Beam (FEI, currently Thermofisher, Eindhoven, The Netherlands)) was performed using an acceleration voltage set from 5 to $25 \mathrm{KeV}$ and acquiring secondary electrons. The elemental composition of materials was performed by an energy dispersive X-ray spectroscopy (EDX) microprobe (EDAX analyzer (AMETEK BV, The Netherlands)) connected to the SEM.

The TEM analysis (JEOL-JEM 2100; JEOL, Italy) was performed at $120 \mathrm{kV}$. The material powders were sonicated for $10 \mathrm{~min}$ in $1 \mathrm{~mL}$ of MilliQ water and then $3 \mu \mathrm{L}$ of the suspensions were deposited on Formvar carbon-coated 200 mesh copper grids (Agar Scientific, USA) before drying overnight in a desiccator. An energy dispersive X-ray analysis (EDX) with the X-Flash Detector 5030 (Brüker, Italy) coupled with the microscope was used for the element identification performed at $120 \mathrm{KV}$ in TEM or STEM mode.

\section{Reported Results of Characterization}

\subsection{Silica Fume (SF)}

Silica fume, or microsilica, is a fine non-crystalline powder generated in electric arc furnaces. It is a by-product of silicon or ferro-silicon alloy processing. SF consists of the fine particles with a specific surface about six times larger than cement. It is known that SF comes in the three forms of powder, condensed, and slurry. Its color varies from light to dark grey as a function of manufacturing processes, such as wood chip composition, furnace temperature, ratio of wood chip to the coal used, exhaust temperature, and type of metal produced [25]. The characterization of SF showed that its particles had a diameter ranging from 20 to $500 \mathrm{~nm}$ [26,27], with a specific surface area of $220 \mathrm{~m}^{2} / \mathrm{g}$, bulk density of $200-350 \mathrm{~kg} / \mathrm{m}^{3}$, and porosity of 0.84 . Figure 2 shows the TEM and EDX analysis of 
SF powder. The TEM images revealed the presence of spherical particles assembled in agglomerates, which are formed during collection and cooling processes. The elemental analysis showed a high percentage of silicon and oxygen, as confirmed by the literature [28,29].

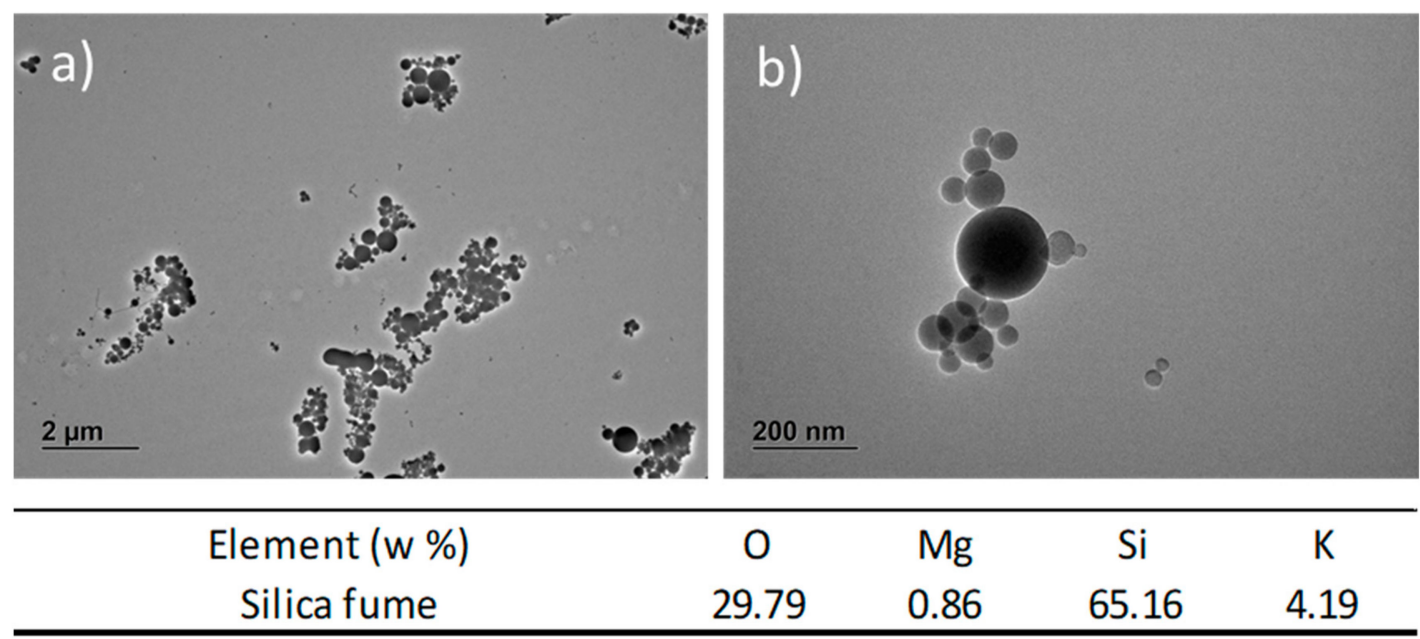

Figure 2. TEM images (a,b) of silica fume sample. Energy dispersive X-ray (EDX) analysis in TEM mode was also reported (data are expressed in weight \%).

The X-ray diffraction (XRD) pattern revealed the presence of an amorphous phase, a broadened peak at around $2 \theta=22^{\circ}$, and cristobalite, which describes the small presence of crystalline $\mathrm{SiO}_{2}$ formed during the production process (see Figure 3) $[26,30,31]$.

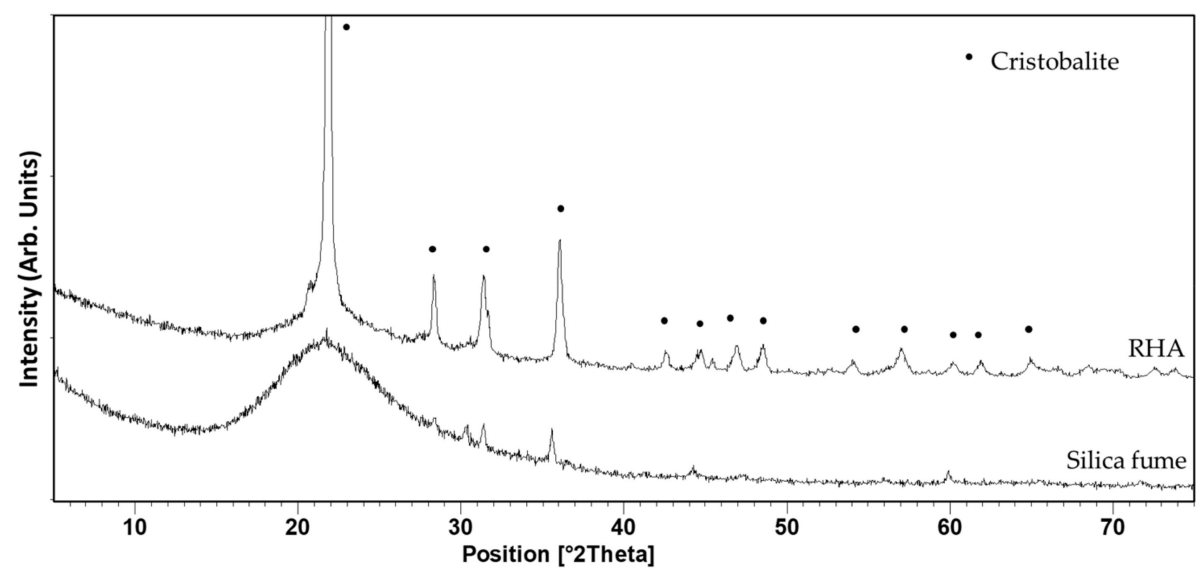

Figure 3. XRD spectra of rice husk ash (RHA) (gray) and silica fume (black).

Thus, the mineral characterization of amorphous silica showed silica and/or silico-aluminate-rich materials. In the frame of the COSMOS (Colloidal Silica Medium to Obtain Safe inert: the case of incinerator fly ash) project [32], it was demonstrated that the presence of amorphous silica in SF was fundamental to heavy metal stabilization. The chemical composition of SF showed that other oxide metals, such as $\mathrm{CaO}, \mathrm{Al}_{2} \mathrm{O}_{3}, \mathrm{MgO}, \mathrm{Na}_{2} \mathrm{O}$, and $\mathrm{K}_{2} \mathrm{O}$, could also be present, counted only in small percentages. A low amount of $\mathrm{MgO}$ was detected in most of the raw materials; however, a slightly higher quantity was found in the Fe-Cr-Si fume, which may not be deleterious to concrete. The percentage of carbon varied between 0.5 and $2 \%$. SF had a different mineralogical composition compared to the natural pozzolans that essentially consisted of an amorphous silica structure with very little crystalline particles. Therefore, SF was the most active pozzolan [33]. Further studies have tested the mechanical properties of cement and concrete after SF addition [34-36]. 
Bearing in mind that SF is a by-product of a well-controlled process, its variation in chemical composition would be expected to be insignificant.

\subsection{Rice Husk Ash (RHA)}

Rice husk $(\mathrm{RH})$ is an agricultural by-product material, which represents approximately $20 \%$ of the rice weight. $\mathrm{RH}$ is characterized by $50 \%$ cellulose, $25-30 \%$ lignin, and $15-20 \%$ silica [33]. Rice husk ash (RHA), generated when rice husk is burnt, is classified as an artificial pozzolan ash and is a very reactive material. Calculations demonstrate that nearly $50 \mathrm{~kg}$ of RHA is developed when $200 \mathrm{~kg}$ of $\mathrm{RH}$ is burnt. Burning conditions affect the particle size and specific surface area of ash. Therefore, the temperature and environment of burning yields are the key parameters that cause differences in the RHA composition. Furthermore, completely burnt RH is grey to white in color, while partially burnt RHA is blackish. Upon burning, cellulose and lignin are removed from RH, leaving behind silica ash. Indeed, the chemical composition of RHA has demonstrated that nearly $90 \%$ is composed by $\mathrm{SiO}_{2}$, and the other part by metal oxides, such as $\mathrm{Al}_{2} \mathrm{O}_{3}, \mathrm{MgO}, \mathrm{Fe}_{2} \mathrm{O}_{3}, \mathrm{CaO}, \mathrm{Na}_{2} \mathrm{O}$, and $\mathrm{K}_{2} \mathrm{O}$ [24,33-38]. The relevant amount of $\mathrm{SiO}_{2}$ makes this kind of ash highly porous and lightweight, with a very high external surface area. Moreover, this waste ash material may be used as a precursor of silica gel $[39,40]$. The efficiency of heavy metal stabilization from MSWI fly ash using RHA during the COSMOS-RICE (Colloidal Silica Medium to obtain Safe Inert, from RICE husk ash) project has already been proven $[32,40]$. The advantage of this low-cost technology is the sustainability, using wastes as raw materials. The mixing of RHA with other MSW derived from incineration has resulted in an effective approach for heavy metal entrapment [37,39,41]. After RH burning, the amorphous silica is converted in its crystalline phase. In the literature, different studies have already highlighted the temperature and time effect on the silica transition phases [42,43]. The XRD pattern of RHA is reported in Figure 3, where it is compared with the SF spectrum. The RHA spectrum shows the presence of cristobalite $\left(\mathrm{SiO}_{2}\right)$ as the only crystalline phase, as reported by Bosio [40]. The SF spectrum appears similar to that of RHA; however, cristobalite peaks are poorly developed due to the predominance of the amorphous phase, which is important during heavy metal immobilization. As explained by Bosio [40] in the extracted silica, the cristobalite phase was not identified, increasing the reactivity of silica for heavy metal stabilization in this way.

\subsection{Coal Fly Ash (CFA)}

CFA is a by-product generated during the pulverized coal combustion process in thermal power plants. The characterization of CFA by means of XRD revealed quartz $\left(\mathrm{SiO}_{2}\right)$ and mullite $\left(\mathrm{Al}_{4.75} \mathrm{Si}_{1.26} \mathrm{O}_{9.63}\right)$ as the major non-magnetic fractions present in the crystalline phase, confirming the data reported by Bosio et al. (2014), since CFA powders have the same origin [40]. Other studies report that the magnetic phases most present in CFA are magnetite and hematite [44,45]. According to the American Society for Testing and Materials (ASTM) [46], CFA can be categorized as class F fly ash or C.fly ash on the basis of the silica, alumina, and iron amount. In particular, the percentage weight of $\mathrm{SiO}_{2}+\mathrm{Al}_{2} \mathrm{O}_{3}+\mathrm{Fe}_{2} \mathrm{O}_{3}$ is higher than $70 \%$ or between $50 \%$ and $70 \%$ for CFA class $\mathrm{F}$ and $\mathrm{C}$, respectively [47].

On the contrary of SF, the elemental composition of CFA varied, owing to coal heterogeneity. This variation was confirmed by an elemental chemical analysis of leachates performed by the total reflection X-ray fluorescence (TXRF) [17,18]. The obtained results revealed that CFA was mostly aluminosilicate material and the major constituent elements were the following: $\mathrm{Al}, \mathrm{Ca}, \mathrm{Fe}, \mathrm{K}$, and Si [33]. The literature results also confirm the presence of unburned carbon and other elements in trace amount, some of which could become toxic elements due to their ability to accumulate over time [46]. Particle size was the major factor in determining the CFA toxicity. The smaller the size of the particle, the greater its surface area to volume ratio, and the higher its chemical and biological reactivity [48]. A SEM analysis was employed to investigate the morphological characteristics of CFA. The parameters that influence the CFA morphology are combustion temperature, cooling rate, and also 
the chemical composition of CFA particles [49]. The SEM images, reported in Figure 4, demonstrated the presence of irregular, rough surfaces to smooth, spherical shapes with sizes ranging from $0.2-25 \mu \mathrm{m}$. Furthermore, the aggregation of the microspheres with small particle sizes connected to surfaces was identified.
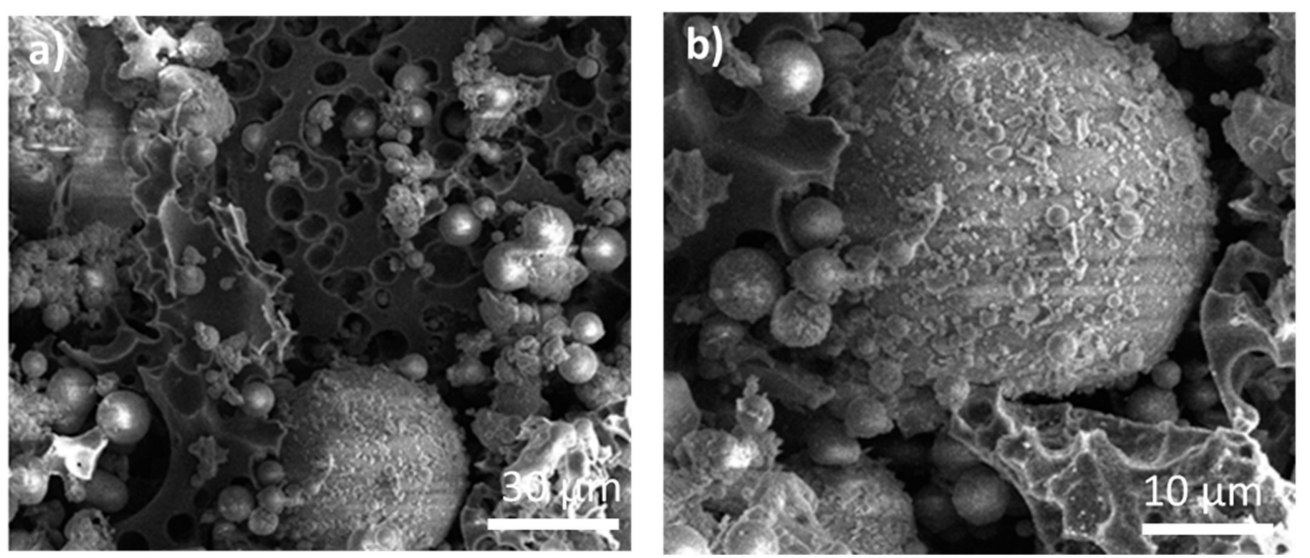

Figure 4. SEM images at different magnifications (4000X (a) and 8000X (b)) of coal fly ash (CFA) powder acquired in secondary electron mode.

As reported by Zanoletti [50], the EDX analysis revealed that the predominant elements in CFA are generally $\mathrm{C}, \mathrm{O}, \mathrm{Si}, \mathrm{Al}, \mathrm{S}, \mathrm{K}, \mathrm{Ca}$, and $\mathrm{Fe}$ in various proportions. Sometimes, some residual amounts of other elements can be detected [51].

The TEM analysis confirmed the spherical shape of CFA particles and the presence of agglomerates, as is shown in Figure 5. Moreover, EDX maps allow the elemental distribution of the sample to be investigated. The EDX chemical analysis showed a non-homogeneous elemental distribution. Indeed, $\mathrm{Al}$ is found in the proximity of $\mathrm{Si}$ and often co-localized, reflecting the presence of alumina-silicate compounds and also the mullite phase, corroborating the results of the XRD patterns and SEM analysis [52]. On the contrary, Fe and Ca demonstrate a homogenous distribution on the agglomerate surface. Our TEM data agreed with the finding of Chen [53], who reports the presence of alumina-silicate phases.
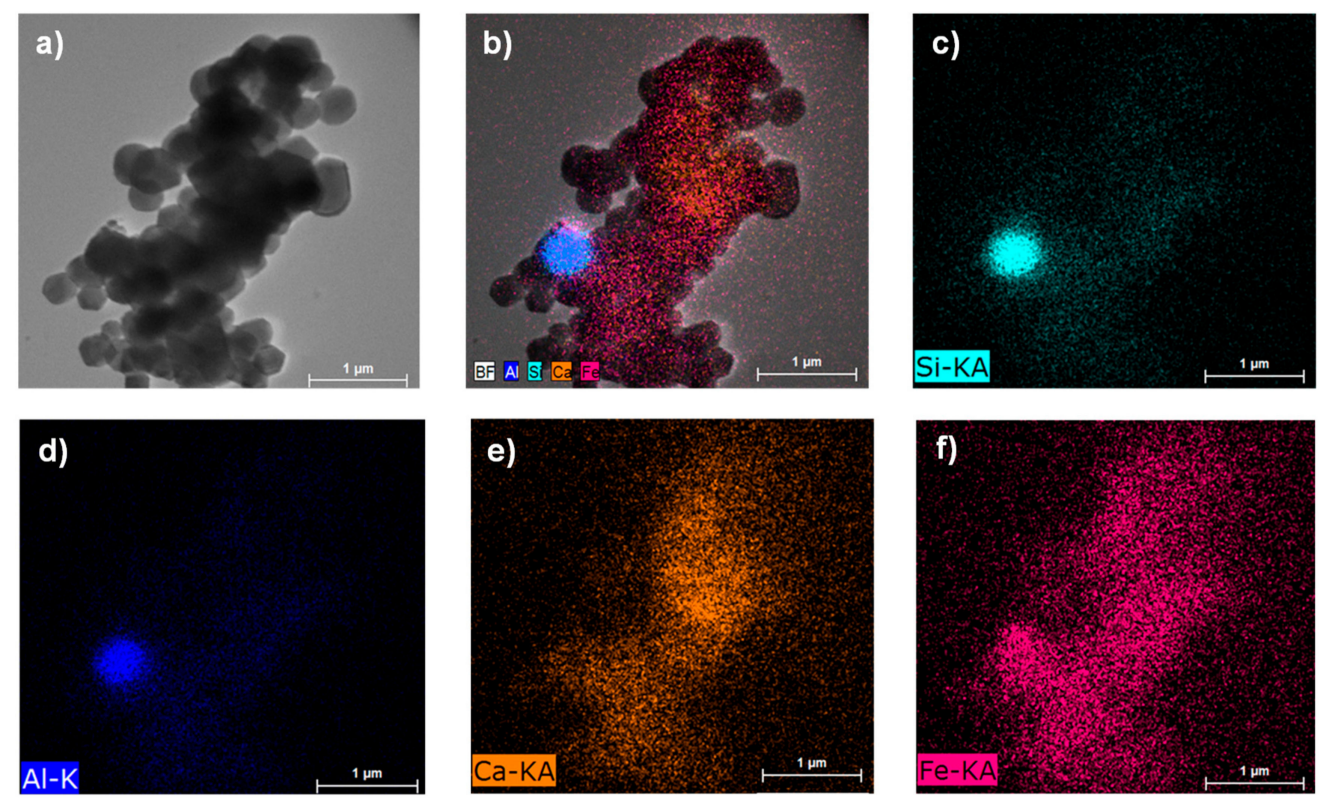

Figure 5. EDX maps in STEM mode of CFA (a,b), $\mathrm{Si}(\mathbf{c}), \mathrm{Al}(\mathbf{d}), \mathrm{Ca}(\mathbf{e})$, and $\mathrm{Fe}(\mathbf{f})$. 


\subsection{Flue Gas Desulfurization Residue (FGD)}

FGD is another by-product resulting from current coal combustion processes. The use of dry processes, based on lime or sodium reagents, is widespread for sulfur dioxide $\left(\mathrm{SO}_{2}\right)$ emission removal in the coal thermal power plant. The FGD material produced from these processes is generally landfilled together with BA and FA materials. In the frame of waste management technologies, the physical and chemical characterization of FGD enables a more detailed assessment of beneficial and safe end-use options. Moreover, it provides a greater level of understanding relative to proper landfill management or the operational considerations for their correct reuse.

The composition of FGD residues is very variable. The residues derived from forced oxidation processes are mainly characterized by $80 \%$ of gypsum mixed with fly ash, although many residues contain less gypsum (20-50\% of the bulk material). FGD residues are very stable in atmospheric conditions at room temperature [54].

The FGD residues contain two main components: a silico-aluminous fly ash part and calcic FGD phases. The FGD XRD pattern identified portlandite $\left(\mathrm{Ca}(\mathrm{OH})_{2}\right)$ as the main mineral phase present in this material, followed by calcium sulphite hemihydrate (hannebachite, $\mathrm{CaSO}_{3} \cdot 0.5 \mathrm{H}_{2} \mathrm{O}$ ) and gypsum $\left(\mathrm{CaSO}_{4} \cdot 2 \mathrm{H}_{2} \mathrm{O}\right)[17,55]$. In the literature, the XRD spectrum of FDG residues also revealed the presence of $\mathrm{SiO}_{2}$, mullite, and hematite, which derived from the presence of FA in the sample. On the other hand, the semi-dry FGD ash showed the existence of some amorphous vitreous material and unburned carbon [54].

The elemental chemical analysis of leachate FGD pointed out $\mathrm{S}$ and $\mathrm{Ca}$ as the major constituents $[18,39,56]$. Other than $\mathrm{S}$ and $\mathrm{Ca}$, FGD ashes are dominated by the presence of $\mathrm{Al}, \mathrm{Fe}$, and Si [57].

The leaching solution of FGD enhances the lack of large amounts of soluble heavy metals. A low $\mathrm{Zn}$ amount was found in the FGD leaching solution, while $\mathrm{Pb}$ was lower than the detection limit. A quantitative analysis revealed that $\mathrm{Cr}, \mathrm{Mn}, \mathrm{Fe}$, and $\mathrm{Cu}$ were found in trace concentrations [17].

The changes in the elemental content of FGD were mainly due to the addition of gypsum granules in the desulfurization tower and the $\mathrm{SO}_{2}$ removal by $\mathrm{CaO} / \mathrm{CaCO}_{3}$. The increase of $\mathrm{S}$ and $\mathrm{Ca}$ in FGD residues could be related to the entrainment of dissolution and gypsum slurry, where $\mathrm{S}$ and $\mathrm{Ca}$ in gypsum and limestone were the main elements [58].

The morphology of FGD particles before and after desulfurization by SEM was performed. Before desulfurization, the particles were fairly dispersed with an irregular spherical shape, while the agglomerates increased after desulfurization. As reported in Figure 6, the FGD particles were agglomerated together to form irregular and dense structures. A further study focused on the comparison of the morphology of FGD residues deriving from a plant and steel factory revealed noticeable differences [54]. The FGD particles from steel factories were characterized by irregular shapes, smooth surfaces, and loose constructions, while semi-dry FGD ash from the thermal power plant included some FA, had a rough surface, and a micro-porous structure. Particle size was another difference between two types of FGD. The FGD particles deriving from the power station are usually bigger in size than those of the steel factory-around $1-50 \mu \mathrm{m}$ and $0.5-25 \mu \mathrm{m}$, respectively. 

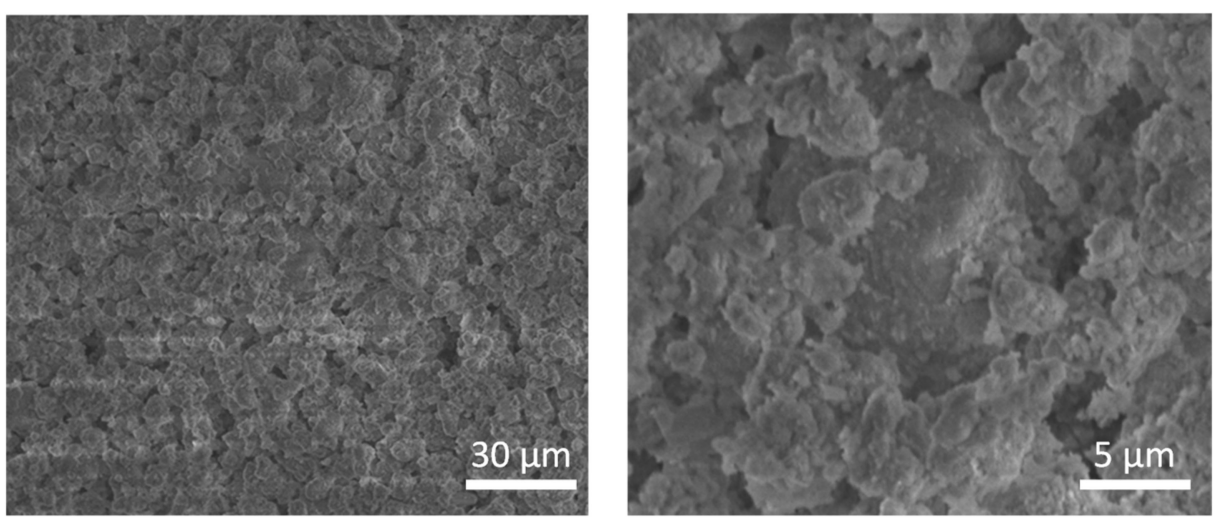

Figure 6. SEM images of flue gas desulfurization (FGD) reported at different magnifications.

\subsection{Stabilized Fly Ash (FA)}

It has already been reported that SF (COSMOS project) [56] and RHA (COSMOS RICE project) [37] can be used to stabilize FA deriving from the incineration of municipal solid waste. Recently, in the frame of the RENDERING (Recupero ENergetico dei fanghi di DEpurazione e loro Riutilizzo, IN alternativa ad alcune risorse naturali, per la produzione di compositi Green) project, it was also demonstrated that BA [17] could be applied as a heavy metal stabilizer. This is an example of a zero-waste treatment. Indeed, this stabilization technology involved the use of ashes (FA and BA) derived from the same industrial process.

COSMOS concerned a mixing of $220 \mathrm{~mL}$ of MilliQ water with $130 \mathrm{~g}$ of FA, $30 \mathrm{~g}$ of CFA, $40 \mathrm{~g}$ of FGD, and $20 \mathrm{~g}$ of SF. The COSMOS RICE was prepared by mixing $200 \mathrm{~mL}$ of MilliQ water with $97.5 \mathrm{~g}$ FA, $15 \mathrm{~g}$ of CFA, $20 \mathrm{~g}$ of FGD, and $8.65 \mathrm{~g}$ of RHA [24]. Finally, the last process (RENDERING project) required the mixing of $200 \mathrm{~mL}$ of MilliQ water, $130 \mathrm{~g}$ of FA, $30 \mathrm{~g}$ of CFA, $40 \mathrm{~g}$ of FGD, and $20 \mathrm{~g}$ of BA.

After the mixing, the compounds were left out at room temperature for two months to allow the solidification and stabilization of the samples. The leaching test (according to CEN EN 12457-2 normative) reported in previous works [17] revealed the stabilization of heavy metals (such as $\mathrm{Pb}$ and $\mathrm{Zn}$ ) contained in the MSWI FA. The stabilization process was attributed to the presence of amorphous silica (derived from SF or RHA or BA) and carbonation reaction $[59,60]$. The carbonation reaction had twofold advantages. First of all, it reduced the leachate $\mathrm{pH}$ and, consequently, made the heavy metal stabilization more efficient. Secondly, it involved the $\mathrm{CO}_{2}$ sequestration from the environment. It was recently calculated that the stabilized material (obtained with BA) can sequestrate $90 \mathrm{kgCO}_{2} / \mathrm{kg}$ of ashes [60].

The XRD pattern of the stabilized samples with RHA, prepared according to the procedure reported $[39,40]$, revealed the presence of the following phases: calcite $\left(\mathrm{CaCO}_{3}\right)$, halite $(\mathrm{NaCl})$, gypsum $\left(\mathrm{CaSO}_{4} \cdot 2 \mathrm{H}_{2} \mathrm{O}\right)$, thaumasite $\left[\mathrm{Ca}\left(\mathrm{SO}_{4}\right)\left[\mathrm{Si}(\mathrm{OH})_{6}\right]\left(\mathrm{CO}_{3}\right) \cdot 12 \mathrm{H}_{2} \mathrm{O}\right]$, quartz $\left(\mathrm{SiO}_{2}\right)$, and potassium chloride $(\mathrm{KCl})$ [37].

In the literature, the elemental chemical composition of RHA from different origins has already been reported [24]. It was demonstrated that the soils influenced the chemical composition of RH. Some studies reported a barrier effect of husk: some heavy metals accumulated more in the rice husk instead of the rice [61]. The application of RHA as a possible stabilizer of MSWI FA was studied. A comparison between the elemental concentration of raw powders and the stabilized sample using RHA highlighted a reduction in the potentially toxic metals' leachability [37].

The TEM observations (see Figure 7) revealed that the stabilized sample with RHA contained solid spherical particles ranging from approximately 0.16 to $0.21 \mu \mathrm{m}$ in diameter. The presence of these particles, similar to agglomerates in an amorphous matrix (Figure 7a,b) or similar to some fibrils (Figure 7c), was observed (see the arrows). The TEM images ascribed that this sample had a somewhat filamentous matrix compared to the sample stabilized with bottom ash [17]. Moreover, in this sample, the presence of crystals $(\mathrm{NaCl}, \mathrm{KCl})$ was observed. 

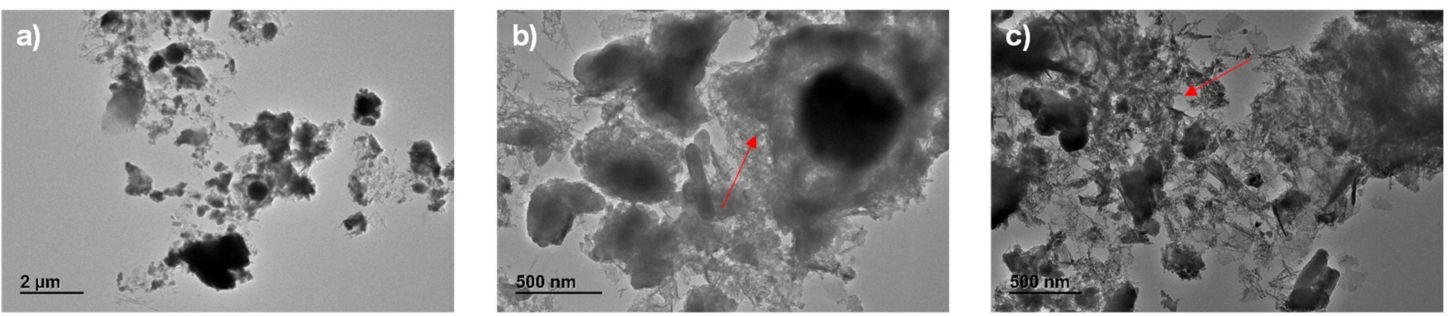

Figure 7. TEM images of stabilized sample with RHA showing the presence of solid spherical particles resembling agglomerates in an amorphous matrix $(\mathbf{a}, \mathbf{b})$ and in fibrils (c).

Figure 8 shows the TEM-EDX maps of $\mathrm{Si}, \mathrm{Fe}, \mathrm{P}$, and $\mathrm{Pb}$ obtained from the stabilized sample with RHA.
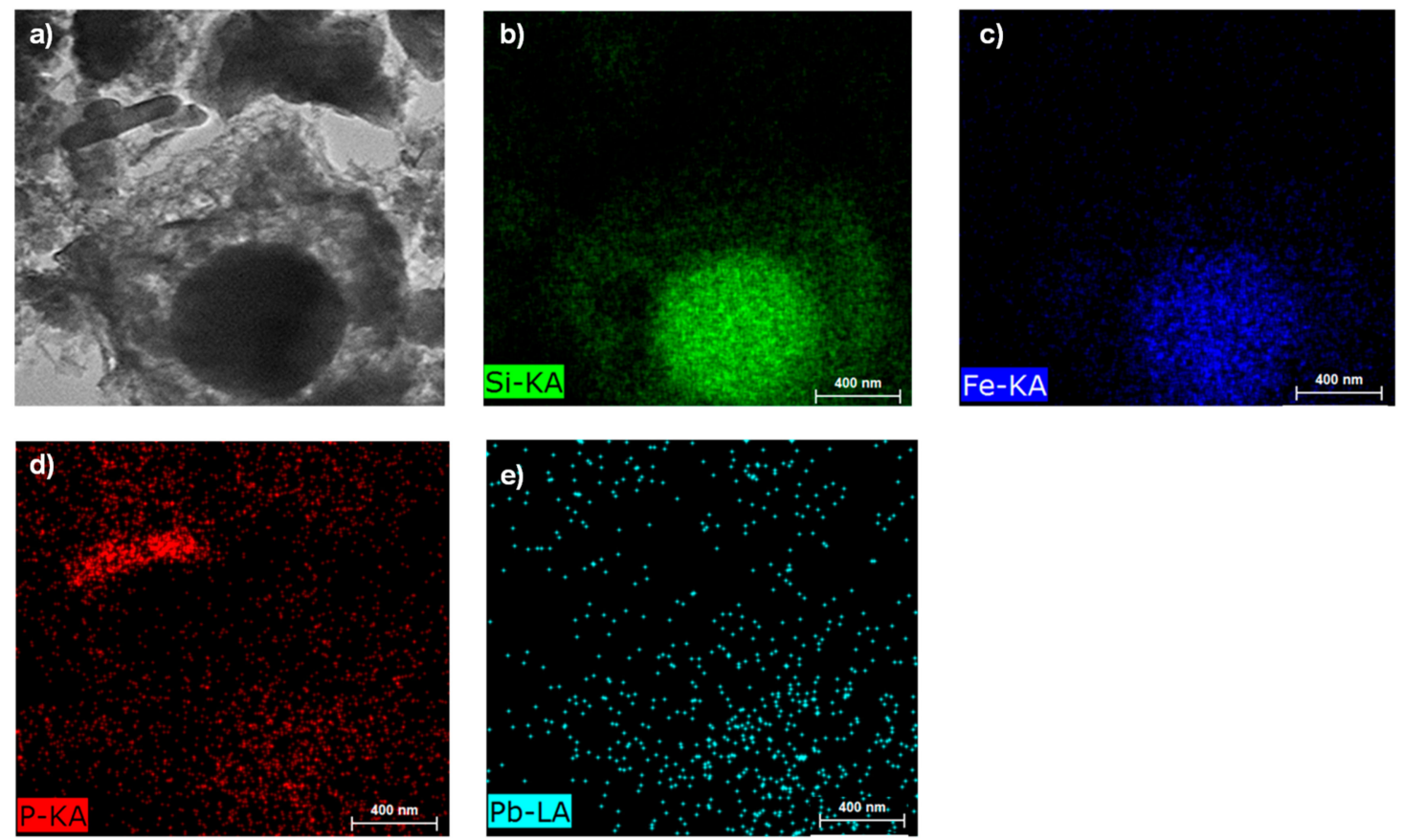

Figure 8. TEM image (a) and EDX maps of $\mathrm{Si}(\mathbf{b}), \mathrm{Fe}(\mathbf{c}), \mathrm{P}(\mathbf{d})$, and $\mathrm{Pb}(\mathbf{e})$ distribution in suspended stabilized sample obtained by mixing MSWI FA, CFA, FGD, and RHA.

The EDX maps in STEM mode, which are reported in Figure 8a-e, were performed from a single particle localized in a small portion of the stabilized sample. The elemental distribution showed that $\mathrm{Pb}$ was mostly co-localized in proximity to silicon (Figure 8e), as already proven with the bottom ash stabilized sample [17]. Fe appeared to be co-localized with a $\mathrm{SiO}_{2}$ particle. $\mathrm{P}$ demonstrated a homogeneous distribution, and the more intense area suggested the presence of $P$ salts in the stabilized sample. The EDX analysis reported $\mathrm{Si}$ and Fe as the major elements, with percentages of 77.2 and 19.3, respectively, while the $\mathrm{P}$ and $\mathrm{Pb}$ concentrations were lower than $2 \%$.

The application of BA in the field of heavy metal stabilization is strongly supported, since it is considered as a new urban mining source. According to Assi [17], the stabilization technology was attributed to the carbonation process and the formation of calcium silicate hydrate $(\mathrm{C}-\mathrm{S}-\mathrm{H})$ compounds. Moreover, thanks to the pozzolanic properties of BA, it is recommended to use the finest particles with the aim of increasing the specific surface area and the reactivity of the amorphous phases. On the contrary, the bigger particles of BA are commonly employed in construction and building engineering. 


\section{Applications}

\subsection{Silica Fume}

The reduction of Portland cement content for economic reasons, the increase the strength, the durability of concrete, and the reduction of alkali-aggregate reactions is considered the main cornerstone for the silica fume application in building engineering [14]. For this reason, it is known as a super pozzolan for the improvement properties of the cements. Indeed, the application of silica in concrete dates back to early 1950 [33]. Although, its incorporation has benefits on the cement concrete properties, the maximum amount of SF instead of cement should be between $7 \%$ and $9 \%$ by the mass of cementation materials. In addition, the possible presence of sulfate and chloride in SF has a relevant role in this application field. Indeed, a high concentration of sulfate may contribute to the expansive reactions in concrete causing the concrete cracking phenomenon, while the chloride ions may migrate through the concrete over time and an accelerated corrosion reaction may initiate if there is any embedded steel [62].

For these reasons, SF can be applied as a replacement for fine aggregates in material constructions (such as cement, concrete, bricks, and ceramic tiles) and filler in plastics [63,64] and paints. Recently, SF was also employed to produce mesoporous silica [65]. It was also demonstrated that SF can be used to trap the As contained in coal fly ash. Different studies revealed that mixing SF with other ashes, such as FA, BA, CFA, and FGD, allows the concentrations of leachable heavy metals, particularly $\mathrm{Pb}$ and $\mathrm{Zn}$, to reduce $[17,66]$. Moreover, this low-cost technology, based on the use of wastes and by-products containing amorphous silica, promotes the $\mathrm{CO}_{2}$ sequestration [60].

Being classified as a light-weight material, SF is a feasible candidate to be incorporated in phase changes material for thermal energy storage in buildings $[67,68]$.

In the last few years, in the frame of Azure Chemistry [69], a new porous and sustainable material (SUNSPACE "Sustainable materials Synthesized from by-Products and Alginates for Clean air and better Environments") was synthesized to promote PM sequestration in urban areas [26]. SUNSPACE synthesis involves the use of industrial by-products and low-cost materials, such as sodium alginate and sodium bicarbonate. The thermal decomposition of bicarbonate at a low temperature $\left(70{ }^{\circ} \mathrm{C}\right)$ allows the formation of ink bottle-shaped pores. This particular shape is suitable for the capturing of fine and ultrafine PM, which is the most dangerous for human health. Various experimental designs were tested with the aim of investigating the capacity of a new porous hybrid material to trap fine and ultrafine PM [26,70]. It is estimated that the SUNSPACE ability of PM entrapment is equal to $30 \mathrm{~g} / \mathrm{m}^{2}$. SUNSPACE used as a coating on all city surfaces (for example on walls, roofs, and so on) appears very promising to reduce airborne PM in urban areas. In addition, SUNSPACE can be regenerated by rainfall, as demonstrated in previous works $[26,69,71]$. From an environmental point of view, the sustainability of this material was evaluated according to a new method proposed in [72]. The energies required in the SUNSPACE synthesis are very low in comparison to other materials that are widely used in air filter realization [69].

\subsection{Rice Husk Ash}

RHA is commonly used as an alternate source of silica [41,73].

The main application field of RHA counts in the concrete and cement materials [74-76]. Different advantages are promoted using RHA in cement and concrete as a pozzolanic material. Some of these are the improvement of mechanical properties (strength and durability), the reduction of material costs due to cement saving, and the environmental benefits related to the reuse of waste material and the reduction of $\mathrm{CO}_{2}$ emissions. It is worth pointing out that RHA may be obtained with high pozzolanic activity if the burning temperature is below $700^{\circ} \mathrm{C}$. The existence of non-reactive silica minerals, such as cristobalite and tridymite, affects the pozzolanic activity of the ash. Although grinding is proposed to increase the fine fraction of the pozzolanic material, Mehta [77] has claimed that this procedure, with a high degree of fineness, should be avoided, since the pozzolanic activity is mainly 
given by the internal surface area of the particles. An addition of RHA to the concrete mixtures increases the cohesiveness and makes the concrete slightly stiffer. The higher the amount of RHA in the concrete mixture, the lower the slump of the mixture. Zhang studied the influence of the substitution of $10 \%$ of RHA instead of cement [78]. This replacement in concrete highlighted a higher compressive strength than the control concrete mixture, but lower than the concrete where silica fume was added. Other studies that focused on the investigation of the RHA's role on the sulfate resistance of concrete revealed an increase of the compressive strength of up to 2 months. This is probably related to the hydration of calcium silicates and the pozzolanic reactions of blended cements [79]. Cements with a high content of RHA have lower porosity because of improved particles packing the density of the blended material, leading to a reduced volume of larger pores [80].

Another explored RHA application is its employment for metal absorption, such as $\mathrm{Pb}$ and $\mathrm{Zn}[81,82]$, which are the main contaminants of wastes. In this frame, RHA has already been tested as a stabilizing agent for heavy metal entrapment on MSWI FA due to the presence of amorphous silica $[18,24,41]$. The high content of amorphous silica in RHA and the porous structure of the particles with a very large surface area are two key parameters responsible for its reactivity. Indeed, the combination of burning temperature and time of up to $700{ }^{\circ} \mathrm{C}$ for less than $1 \mathrm{~h}$ is reported as the optimum solution for having silica in an amorphous form $[43,83]$. At a higher burning temperature, crystalline silica is produced and, thus, reduces the reactivity of RHA. Nevertheless, the transition of amorphous silica to the crystalline phase affects either its stabilization properties or health issues: for example, inhalation can lead to silicosis disease. Therefore, the presence of crystalline silica reduces the potential application markets for RHA.

Furthermore, RHA owns excellent insulating and absorbent properties. These features enable its application in industrial processes, such as steel factories, and in the manufacturing of insulation for houses and refractory bricks, or to absorb oil on hard surfaces, as well as to filter arsenic from water.

\subsection{Coal Fly Ash}

Recycling CFA can not only be a valuable alternative to landfill, but can also bring economic and environmental benefits. A large portion of CFA is generally reemployed in cement and concrete manufacturing $[84,85]$. Other application fields of CFA reported in literature are: soil amelioration, catalysis, environmental protection, depth separation, zeolite synthesis, and valuable metal recovery $[84,86]$. Nevertheless, other application fields are foreseen for the complete reuse of this abundant by-product.

Globally, it is estimated that about 7.8 billion tons of CFA are produced per year-only $53.3 \%$ of which are currently recycled $[85,87]$. New applications of CFA are demonstrated in the field of pollutants adsorption [88]. Hence, CFA has successfully been tested as an adsorbent of anionic surfactants $[14,50]$. CFA was used as a sustainable and low-cost material instead of activated carbon, the commercial adsorbent widely used in adsorption processes. CFA has shown good performance in the removal of sodium dodecyl sulfate (SDS) as a model of anionic surfactants, with up to $96 \%$ with $100 \mathrm{~g} / \mathrm{L}$ of CFA. The sustainability of the adsorbent was evaluated in terms of embodied energy (EE) and carbon footprint (CF) according to the new simplified method reported in recent works [72]. Although the $\mathrm{CO}_{2}$ emission during the production of activated carbon and CFA is comparable, a great difference is evaluated in terms of energy primary production. Indeed, the EE values are estimated as higher than $20 \mathrm{MJ} / \mathrm{kg}$ and lower than $1 \mathrm{MJ} / \mathrm{kg}$ for activated carbon and CFA, respectively.

CFA could be used as a source of raw material for the synthesis of nanoparticles, as well as the extraction of useful metals, such as $\mathrm{Al}, \mathrm{Si}, \mathrm{V}, \mathrm{Fe}$, and $\mathrm{Ni}$, due to its mineralogical composition. Vitrification seems to be a valuable technology in the field of industrial waste reuse. The results are encouraging for this application possibility due to the total destruction of toxic trace elements and the solidification of heavy metals into the glass matrix generated during the vitrification at a high temperature and the consequent nucleation and crystallization heat processes [89,90]. 
The application of CFA is related to two different classes (C or F). Class $\mathrm{C}$ of CFA is more suitable for the synthesis of $\mathrm{CaO}-\mathrm{Al}_{2} \mathrm{O}_{3}-\mathrm{SiO}_{2}$ (CAS) system glass ceramics. This CAS system can be applied in the field of construction due to its excellent mechanical properties, dimensional stability, and resistance of abrasion and corrosion. On the contrary, class F of CFA is unsuitable for the CAS glass ceramic system and cement additives due to the high amount of $\mathrm{MgO}$ and $\mathrm{Fe}_{2} \mathrm{O}_{3}$. Instead, this class is endorsed for the synthesis of $\mathrm{MgO}-\mathrm{Al}_{2} \mathrm{O}_{3}-\mathrm{SiO}_{2}$ (MAS) system glass ceramic, whose cordierite or mullite are the principal phases. Thanks to the elevated thermal stability and good chemical durability of this MAS system glass ceramic, it is commonly applied in the high temperature field, where an excellent thermal shock resistance is required [47].

\subsection{Flue Gas Desulfurization Residue}

Agriculture is one of the major application fields of FGD thanks to its suitable physical and chemical properties in the remediation of soil quality and crop growth. In this frame, several studies highlight the benefits of FGD product uses on agricultural lands, such as a soil amendment [91], ameliorating acidic soils, improving soil structure to increase infiltration and water storage, reducing soil erosion and the movement of sediments, remediating sodic soils, providing a nutrient source for crops, increasing crop yield, and stabilizing and enriching organic composts [92]. In the case of the alfalfa herb plant (Medicago sativa L.), FGD residue is considered a readily available B source that is mostly necessary in the growing season when native soil B availability decreases [93]. Other than B, FGD incorporation into soil also causes an increase of other elements, such as Mo, Se, and extractable Ca. The uses of FGD residues at an optimum rate (around 2.5\%) has an advantage on crop establishment, alleviating surface acidity, as well as B and Mo deficiencies [94].

It is known that FGD also contains potentially toxic elements. The presence of gypsum in FGD has somehow limited its uses in agriculture compared to other industries. Therefore, strong attention to the long-term studies of the FGD gypsum impact on soil conditions, heavy metal uptake and transfer, crop growth and quality, and continuous soil and water monitoring is required [95].

On the other hand, FGD gypsum is presented as an advantageous alternative to be used in place of natural gypsum in cement composition [96]. Due to the high $\mathrm{CaSO}_{4}$ content in desulfurization gypsum, it has been widely used to produce wallboard, cement retardant, and gypsum board in concrete engineering $[97,98]$. Further cases of FGD applications count for the production of Portland cement in flowable fill in mine reclamation and in aerated concrete blocks.

FGD residues in cement compositions may not only be used as a retarder, but also to enhance the strength of cement mortar and reduce the amount of water needed under the condition of normal cement consistency. For this reason, important attention should be paid to control the ratio between desulphurization residues and gypsum in order to modulate the cement setting time effectively [99].

The application of FGD residues as a filler in gneiss-based asphalt mixture has significant benefits both from an environmental and economic point of view. The results enlighten that FGD residues can partly improve the moisture resistance and crack resistance of the gneiss asphalt mixture [100].

FGD has demonstrated a good capacity in the heavy metal immobilization of fly ash deriving from the municipal solid waste incinerator [101].

Nowadays, there is a growth demand of ammonium sulfate amounts, since it is a valuable nutrient source for both nitrogen and sulfur for growing plants. It is considered an attractive solution to convert some of the FGD-gypsum to ammonium sulfate, which also reduces problems related to their disposal. Currently, it is assessed that the production of ammonium sulfate from FGD residues react with ammonium carbonate in an aqueous solution [102].

\subsection{Stabilized Fly Ash}

The reuse of stabilized FA as a filler of several composites was proposed [14,20,37]. 
The most promising results were obtained using these powders as a filler in plastic composites [103]. Several examples have already been proposed, while also discussing the mechanical performances of the obtained composites in comparison to the composites containing natural resources (calcite- $\mathrm{CaCO}_{3}$ ) [104].

The production of polypropylene (PP) composite materials using the stabilized FA as a filler through the injection molding machine was made. The stabilized ash was obtained by mixing the ashes FA, CFA, FGD, and BA with tap water at room temperature using the pilot plant located in the Brescia incinerator, as already reported by Assi [17]. In order to promote the carbonation reaction that contributes to the stabilization of heavy metals, the material obtained after the mixing process was aged for 1 year, as discussed by [60]. As mentioned by Assi [104], a periodic leaching test was performed in order to control the stability of the sample.

Figure 9 shows the scheme of the machine used to produce the samples that were fed by granules of PP and stabilized fly ashes with different percentages by mixing the two components before introducing them into the machine. Figure 9 also shows that using endless screws adopted by the injection molding machine helped not only to melt and push the material outside through the extruder, but also to mix and obtain more homogeneous material. The complete mold filling depended on the viscosity of the composite material, which depended also on the filler charge set and the geometry complex. Figure 10 shows a set of composite samples obtained by the injection molding process with different filler percentages. Figure 10c,d shows that some streaks were present on the surface of the samples with more percentage of filler due to the crushing of stabilized ash grains. This problem can be resolved by adding some colorant product to the mixture.

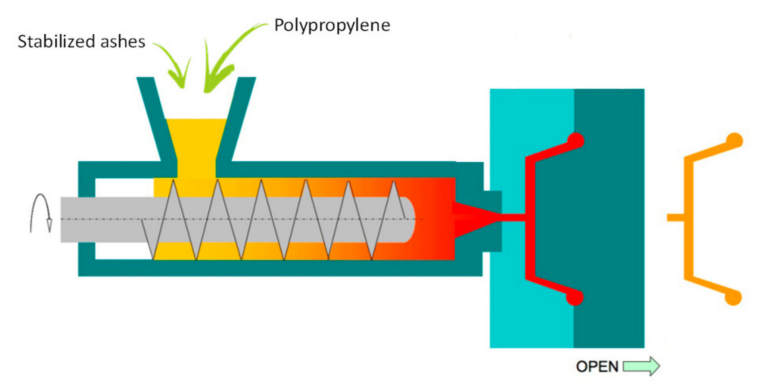

Figure 9. Injection molding machine.
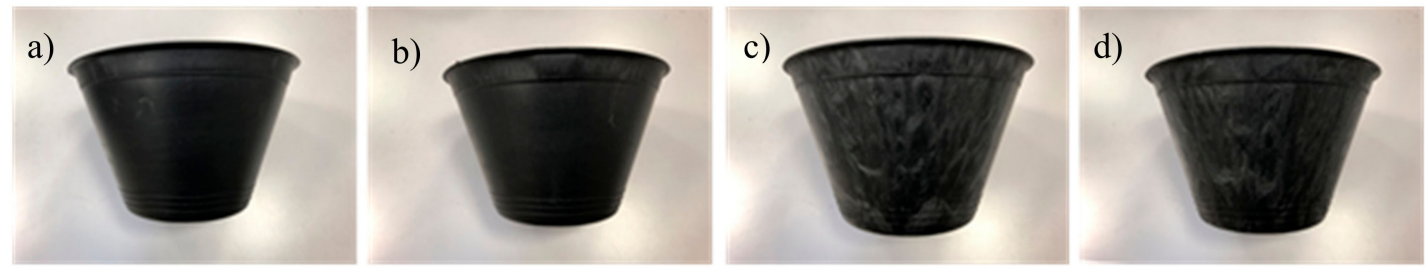

Figure 10. Sample products with different $\%$ of ash: (a) PP, (b) $10 \%$, (c) $20 \%$, (d) $30 \%$.

\subsection{Mechanical Experimental Tests}

This chapter reports new results, which have not been published before, about the mechanical tests performed on composite materials, obtained as described in paragraph 3.5 and compared to the literature data. These tests were obtained on the composites described in Section 4.5.

\subsubsection{Tensile Testing}

The tensile test was performed according to (UNI ISO 527). The specimen geometries used were the dog-bone specimen. The test was conducted by applying a uni-axial load through the ends of the specimen. The results of the test are reported in Table 1 and show that as the weight fraction of filler increased in the composites up to $20 \mathrm{wt} \%$, the results of the tensile strength decreased up to $26.5 \mathrm{MPa}$, the elongation percentage decreased from $121.3 \%$ as the initial value of PP without filler to $11.4 \%$, and 
the tensile modulus increased at high fly ash content. This can be attributed to the fillers that occupied the interstitial volume. There might have been less PP matrices that could have contributed to the tensile strength, as reported by Paliwal [105], and to a bad interfacial bonding between the fly ash and the matrix [106]. Furthermore, as reported by Srivastava [107], the inhibition and propagation of the crack inside the composite material can be attributed to the presence of fly ash particles. The results obtained from the tensile modulus, tensile strength, and breaking elongation were similar to the results reported by Maiti [108] by using $\mathrm{CaCO}_{3}$ as a filler of the PP composite material.

\subsubsection{Three Point Bending Test}

The flexural modulus was obtained through a three-point bending test performed by means of an electromechanical dynamometer according to (UNI ISO 178). The flexural modulus determines how much a sample will bend when a given load is applied, calculated from the slope of the stress vs. The strain deflection curve, as reported by Assi [104]. As reported in Table 1 and as expected, increasing the filler amount in the PP matrix increased the flexural modulus [109]. Due to the addition of fly ash in the composite material, the crystalline of composites increased and the flexural modulus increased. This resulted in an agreement with the results obtained by Gummadi [110] for smaller particle sizes of fly ash, due to higher contact surface. As reported by Sengupta [111], due to the strong interfacial bonding between the fly ash and the PP matrix, the flexural property increased. The results obtained using fly ash as a filler were similar to those obtained using $\mathrm{CaCO}_{3}$, as reported by Yang [112].

\subsubsection{Impact Strength Test}

The impact test (Izod test) was performed according to (UNI ISO 180) and the ASTM standard. The results of the impact test of the composite material are reported in Table 1 . The values of the impact strength decreased, so the energy absorbed in the process of plastic deformation of the matrix material/reinforcement interface decreased by more than $150 \%$ by increasing the percentage of filler. This can be attributed to the high surface occupied by the particles of fly ash, as reported by Gupta [113], and by making the material more brittle due to the limited ability of adopting the deformation [114], and the particles can act as a microcrack initiator [115]. Maiti [108] also reports that increasing the percentage of $\mathrm{CaCO}_{3}$ as a filler of the PP composite decreases the impact strength.

Table 1. Data of mechanical experiments.

\begin{tabular}{cccccc}
\hline Material & $\begin{array}{c}\text { Breaking } \\
\text { Elongation [\%] }\end{array}$ & $\begin{array}{c}\text { Tensile } \\
\text { Strength [MPa] }\end{array}$ & $\begin{array}{c}\text { Tensile } \\
\text { Modulus [MPa] }\end{array}$ & $\begin{array}{c}\text { Flexural } \\
\text { Modulus [MPa] }\end{array}$ & $\begin{array}{c}\text { Impact } \\
\text { Strength [J/m } \mathbf{m}^{2} \text { ] }\end{array}$ \\
\hline $\begin{array}{c}\text { PP } \\
\text { PP }+\begin{array}{c}10 \% \text { stabilized } \\
\text { fly ash }\end{array}\end{array}$ & 121.3 & 27 & 377.3 & 1176 & 5.4 \\
$\mathrm{PP}+\begin{array}{c}20 \% \text { stabilized } \\
\text { fly ash }\end{array}$ & 16.3 & 27.1 & 412 & 1437 & 3.6 \\
\hline
\end{tabular}

\section{Conclusions}

In this review, the results of the characterization of different by-products, incineration residues, and combustion materials produced in a medium-sized city are reported. The characterization of these materials is realized by using various techniques, such as XRD, TXRF, SEM, and TEM, that allow us not only to investigate the material characteristics, but also to better recognize the most suitable strategies to employ them.

The review also resumes the stabilization processes that can be applied to reduce the heavy metal's leachability of toxic wastes. Indeed, due to its toxicity, MSWI fly ash treatment was required before its reuse. To satisfy the circular economy principles and apply the azure chemistry approach, waste and by-products were mixed to obtain a stable and safe material. For example, MSWI fly ash stabilization was performed by mixing this waste with the other residues containing amorphous reactive phases. 
As reported in the literature, the stabilization of fly ash significantly promotes the possibility of investigating the value-added applications of this waste, such as its use as a filler, for example, in plastic composites. Moreover, other investigated promising application fields are presented.

Figure 11 highlights the most suitable applications determined for each type of ash.

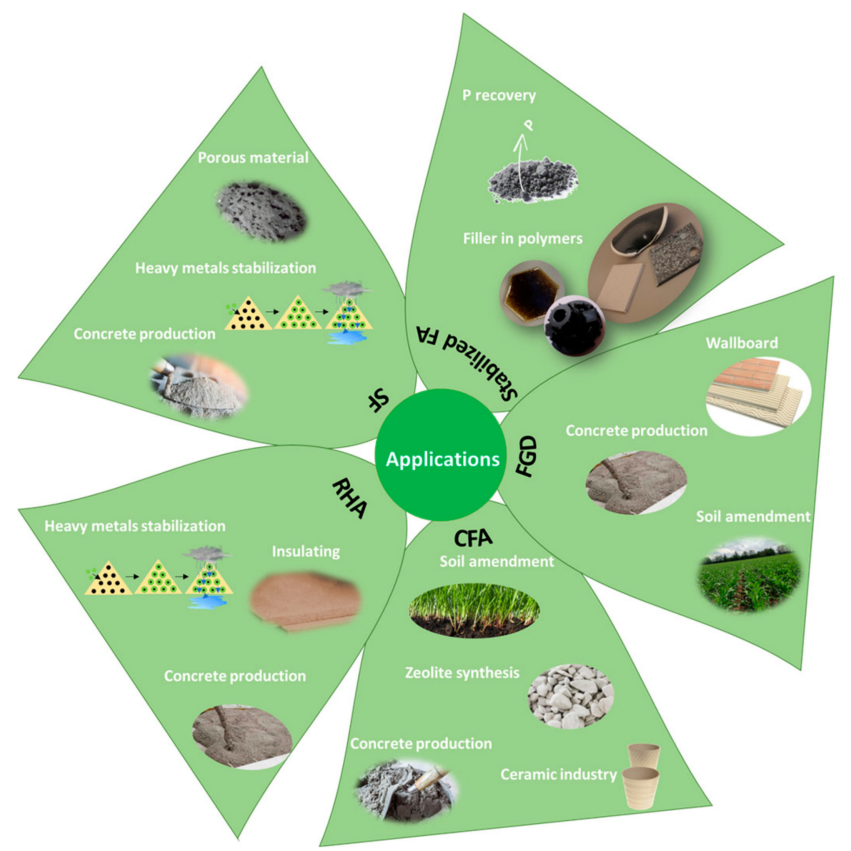

Figure 11. Possible applications of coal fly ash (CFA), silica fume (SF), flue gas desulfurization (FGD), and stabilized fly ash (stabilized FA) with RHA or bottom ash.

For example, the reuse of stabilized fly ash to produce sustainable plastic composites allows natural resources to be preserved, offering environmental and economic benefits.

Author Contributions: Conceptualization, E.B.; formal analysis, A.Z., J.P., A.V., R.L.S.; investigation, A.Z., A.A., and F.B.; data curation, J.P., A.V., and F.B.; writing-original draft preparation, F.B.; E.B.; writing-review and editing, L.E.D., E.B., and J.P.; supervision, F.B. and E.B.; project administration, E.B.; funding acquisition, E.B. and L.E.D. All authors have read and agreed to the published version of the manuscript.

Funding: This research in the frame of the project: "Energy recovery of waste sludge and their re-use as an alternative to some natural resources, for the production of Green composites, RENDERING" is funded by Ministero dell'Ambiente e della Tutela del Territorio e del Mare-Direzione generale dei rifiuti e dell'inquinamento. It is supported by University of Brescia, CSMT, INSTM, and Regione Lombardia.

Disclaimer: The scientific output expressed does not imply a policy position of the European Commission. Neither the European Commission nor any person acting on behalf of the Commission is responsible for the use that might be made of this publication.

Acknowledgments: The experimental data used in this research were generated through access to the Nanobiotechnology Laboratory under the Framework of access to the Joint Research Centre Physical Research Infrastructures of the European Commission (CARPACI project, Characterization of air particulate matter (PM) trapped by a new material coming from industrial waste, Research Infrastructure Access Agreement Nr. 35050). The authors thank Douglas Gilliland, Pascal Colpo, Giulio Cotogno, Giacomo Ceccone, and Robin Bruno Capomaccio for their useful comments on the data analysis.

Conflicts of Interest: The authors declare no conflict of interest. The funders had no role in the design of the study; in the collection, analyses, or interpretation of data; in the writing of the manuscript, or in the decision to publish the results.

\section{References}

1. Gundupalli, S.P.; Hait, S.; Thakur, A. A review on automated sorting of source-separated municipal solid waste for recycling. Waste Manag. 2017, 60, 56-74. [CrossRef] [PubMed] 
2. Abdel-Shafy, H.I.; Mansour, M.S.M. Solid waste issue: Sources, composition, disposal, recycling, and valorization. Egypt. J. Pet. 2018, 27, 1275-1290. [CrossRef]

3. Cogeneration and Thermal Plants|Drupal. Available online: https://www.a2a.eu/en/group/our-plants/ cogeneration-thermal-plants (accessed on 10 May 2020).

4. Obe, R.K.D.; De Brito, J.; Lynn, C.J.; Silva, R.V. Sustainable Construction Materials: Municipal Incinerated Bottom Ash, 1st ed.; Woodhead Publishing: Sawston, UK, 2017; ISBN 9780081009970.

5. Quina, M.J.; Bontempi, E.; Bogush, A.; Schlumberger, S.; Weibel, G.; Braga, R.; Funari, V.; Hyks, J.; Rasmussen, E.; Lederer, J. Technologies for the management of MSW incineration ashes from gas cleaning: New perspectives on recovery of secondary raw materials and circular economy. Sci. Total Environ. 2018, 635, 526-542. [CrossRef] [PubMed]

6. Quina, M.J.; Bordado, J.C.; Quinta-Ferreira, R.M. Treatment and use of air pollution control residues from MSW incineration: An overview. Waste Manag. 2008, 28, 2097-2121. [CrossRef]

7. Ramezanianpour, A.A.; Nikravan, M.; Maknoon, R. Characterization of bottom ash from petrochemical waste incinerator. J. Residuals Sci. Technol. 2011, 8, 189-196.

8. Dou, X.; Ren, F.; Nguyen, M.Q.; Ahamed, A.; Yin, K.; Chan, W.P.; Chang, V.W.C. Review of MSWI bottom ash utilization from perspectives of collective characterization, treatment and existing application. Renew. Sustain. Energy Rev. 2017, 79, 24-38. [CrossRef]

9. European Union, European Waste Catalogue. Available online: https://ec.europa.eu/environment/waste/ framework/list.htm (accessed on 21 April 2020).

10. SEPA Scottish Environment Protection Agency (SEPA); Environment and Heritage Service; Environment Agency. Hazardous Waste, Interpretation of the Definition and Classification of Hazardous Waste; Technical Guidance WM2; Albion Environmental: Ayr, UK, 2003.

11. Struis, R.P.W.J.; Pasquali, M.; Borgese, L.; Gianoncelli, A.; Gelfi, M.; Colombi, P.; Thiaudière, D.; Depero, L.E.; Rizzo, G.; Bontempi, E. Inertisation of heavy metals in municipal solid waste incineration fly ash by means of colloidal silica-a synchrotron X-ray diffraction and absorption study. RSC Adv. 2013, 3, 14339-14351. [CrossRef]

12. Riyad, M.F.; Fuka, M.; Lofthus, R.; Li, Q.; Patel, N.M.; Gupta, S. Novel engineered cementitious materials by using class $\mathrm{C}$ fly ash as a cementitious phase. In Ceramic Transactions; American Ceramic Society: Hoboken, NJ, USA, 2016; Volume 260, pp. 35-43.

13. Goodwin, R.W. Combustion Ash Residue Management: An Engineering Perspective, 2nd ed.; Elsevier: Amsterdam, The Netherlands, 2014; ISBN 978-0-12-420038-8.

14. Bontempi, E. Raw Materials Substitution Sustainability; Springer International Publishing: Cham, Switzerland, 2017; pp. 63-77. ISBN 978-3-319-60831-0.

15. Husgafvel, R.; Karjalainen, E.; Linkosalmi, L.; Dahl, O. Recycling industrial residue streams into a potential new symbiosis product-The case of soil amelioration granules. J. Clean. Prod. 2016, 135, 90-96. [CrossRef]

16. Silva, F.C.; Cruz, N.C.; Tarelho, L.A.C.; Rodrigues, S.M. Use of biomass ash-based materials as soil fertilisers: Critical review of the existing regulatory framework. J. Clean. Prod. 2019, 214, 112-124. [CrossRef]

17. Assi, A.; Bilo, F.; Zanoletti, A.; Ponti, J.; Valsesia, A.; La Spina, R.; Zacco, A.; Bontempi, E. Zero-waste approach in municipal solid waste incineration: Reuse of bottom ash to stabilize fly ash. J. Clean. Prod. 2020, 245, 118779. [CrossRef]

18. Benassi, L.; Pasquali, M.; Zanoletti, A.; Dalipi, R.; Borgese, L.; Depero, L.E.; Vassura, I.; Quina, M.J.; Bontempi, E. Chemical Stabilization of Municipal Solid Waste Incineration Fly Ash without Any Commercial Chemicals: First Pilot-Plant Scaling Up. ACS Sustain. Chem. Eng. 2016, 4, 5561-5569. [CrossRef]

19. Bosio, A.; Zacco, A.; Borgese, L.; Rodella, N.; Colombi, P.; Benassi, L.; Depero, L.E.; Bontempi, E. A sustainable technology for $\mathrm{Pb}$ and $\mathrm{Zn}$ stabilization based on the use of only waste materials: A green chemistry approach to avoid chemicals and promote CO2 sequestration. Chem. Eng. J. 2014, 253, 377-384. [CrossRef]

20. Rodella, N.; Pasquali, M.; Zacco, A.; Bilo, F.; Borgese, L.; Bontempi, N.; Tomasoni, G.; Depero, L.E.; Bontempi, E. Beyond waste: New sustainable fillers from fly ashes stabilization, obtained by low cost raw materials. Heliyon 2016, 2, e00163. [CrossRef] [PubMed]

21. Lichtfouse, E.; Schwarzbauer, J.; Robert, D. (Eds.) Pollutant Diseases, Remediation and Recycling; Springer International Publishing: Cham, Switzerland, 2013; ISBN 978-3-319-02387-8.

22. Mindess, S. Developments in the Formulation and Reinforcement of Concrete; Woodhead Publishing: Sawston, UK, 2019; ISBN 9780128189283. 
23. A2A Ambiente. Available online: https://www.a2aambiente.eu/economia-circolare-crea-valore/tu-brescia/ scopri-impianto-tu-brescia (accessed on 10 May 2020).

24. Benassi, L.; Bosio, A.; Dalipi, R.; Borgese, L.; Rodella, N.; Pasquali, M.; Depero, L.E.; Bergese, P.; Bontempi, E. Comparison between rice husk ash grown in different regions for stabilizing fly ash from a solid waste incinerator. J. Environ. Manag. 2015, 159, 128-134. [CrossRef]

25. Panjehpour, M.; Abang Ali, A.A.; Demirboga, R. A Review for Characterization of Silica Fume and Its Effects on Concrete Properties. Int. J. Sustain. Constr. Eng. Technol. 2011, 2, 1-7.

26. Zanoletti, A.; Vassura, I.; Venturini, E.; Monai, M.; Montini, T.; Federici, S.; Zacco, A.; Treccani, L.; Bontempi, E. A New Porous Hybrid Material Derived from Silica Fume and Alginate for Sustainable Pollutants Reduction. Front. Chem. 2018, 6. [CrossRef]

27. Zhou, C.; Yan, C.; Zhao, J.; Wang, H.; Zhou, Q.; Luo, W. Rapid synthesis of morphology-controlled mesoporous silica nanoparticles from silica fume. J. Taiwan Inst. Chem. Eng. 2016, 62, 307-312. [CrossRef]

28. Chan, Y.W.; Chu, S.H. Effect of silica fume on steel fiber bond characteristics in reactive powder concrete. Cem. Concr. Res. 2004, 34, 1167-1172. [CrossRef]

29. Babu, K.G.; Babu, D.S. Behaviour of lightweight expanded polystyrene concrete containing silica fume. Cem. Concr. Res. 2003, 33, 755-762. [CrossRef]

30. Soliman, N.A.; Tagnit-Hamou, A. Partial substitution of silica fume with fine glass powder in UHPC: Filling the micro gap. Constr. Build. Mater. 2017, 139, 374-383. [CrossRef]

31. Nochaiya, T.; Wongkeo, W.; Chaipanich, A. Utilization of fly ash with silica fume and properties of Portland cement-fly ash-silica fume concrete. Fuel 2010, 89, 768-774. [CrossRef]

32. Project Life11 ENV/IT/000256. Available online: http://www.cosmos-rice.csmt.eu/ (accessed on 21 April 2020).

33. Ramezanianpour, A.A. Cement Replacement Materials: Properties, Durability, Sustainability; Springer International Publishing: Cham, Switzerland, 2014; ISBN 978-3-642-36721-2.

34. Kumar, A.; Roy, D.M. A Study of Silica-Fume-Modified Cements of Varied Fineness. J. Am. Ceram. Soc. 2006, 67, 61-64. [CrossRef]

35. Saad, M.; Abo-El-Eneinf, S.A.; Hanna, G.B.; Kotkata, M.F. Effect of temperature on physical and mechanical properties of concrete containing silica fume. Cem. Concr. Res. 1996, 26, 669-675. [CrossRef]

36. Okoye, F.N.; Durgaprasad, J.; Singh, N.B. Effect of silica fume on the mechanical properties of fly ash based-geopolymer concrete. Ceram. Int. 2016, 42, 3000-3006. [CrossRef]

37. Benassi, L.; Franchi, F.; Catina, D.; Cioffi, F.; Rodella, N.; Borgese, L.; Pasquali, M.; Depero, L.; Bontempi, E. Rice Husk Ash to Stabilize Heavy Metals Contained in Municipal Solid Waste Incineration Fly Ash: First Results by Applying New Pre-treatment Technology. Materials 2015, 8, 6868-6879. [CrossRef] [PubMed]

38. Bosio, A.; Rodella, N.; Depero, L.E.; Bontempi, E. Rice husk ash based composites, obtained by toxic fly ash inertization, and their applications as adsorbents. Chem. Eng. Trans. 2014, 37, 631-636. [CrossRef]

39. Rodella, N.; Bosio, A.; Dalipi, R.; Zacco, A.; Borgese, L.; Depero, L.E.; Bontempi, E. Waste silica sources as heavy metal stabilizers for municipal solid waste incineration fly ash. Arab. J. Chem. 2017, 10, S3676-S3681. [CrossRef]

40. Bosio, A.; Gianoncelli, A.; Zacco, A.; Borgese, L.; Rodella, N.; Zanotti, D.; Depero, L.E.; Siviero, G.; Cinosi, A.; Bingham, P.A.; et al. A new nanotechnology of fly ash inertization based on the use of silica gel extracted from rice husk ash and microwave treatment. Proc. Inst. Mech. Eng. Part N J. Nanoeng. Nanosyst. 2014, 228, 27-32. [CrossRef]

41. Bosio, A.; Rodella, N.; Gianoncelli, A.; Zacco, A.; Borgese, L.; Depero, L.E.; Bingham, P.A.; Bontempi, E. A new method to inertize incinerator toxic fly ash with silica from rice husk ash. Environ. Chem. Lett. 2013, 11, 329-333. [CrossRef]

42. Yeoh, A.; Bidin, R.; Chong, C.; Tay, C. The relationship between temperature and duration of burning of rice-husk in the development of amorphous rice-husk ash silica. In Proceedings of the UNIDO/ESCAP/RCTT, Follow-up Meeting on Rice-Husk Ash Cement, Alor Setar, Malaysia, 20 Janury; 1979.

43. Chopra, S.; Ahluwalia, S.; Laxmi, S. Technology and Manufacture of Rice-Husk Ash Masonry (RHAM) Cement. In Proceedings of ESCAP/RCTT Workshop on Rice-Husk Ash Cement; ESCAP/RCTT: New Delhi, India, 1981.

44. Shoumkova, A.S. Magnetic separation of coal fly ash from Bulgarian power plants. Waste Manag. Res. 2011, 29, 1078-1089. [CrossRef] 
45. Hower, J.C.; Rathbone, R.F.; Robertson, J.D.; Peterson, G.; Trimble, A.S. Petrology, mineralogy, and chemistry of magnetically-separated sized fly ash. Fuel 1999, 78, 197-203. [CrossRef]

46. Alegbe, J.; Ayanda, O.S.; Ndungu, P.; Alexander, N.; Fatoba, O.O.; Petrik, L.F. Chemical, Mineralogical and Morphological Investigation of Coal Fly Ash Obtained from Mpumalanga Province, South Africa. Res. J. Environ. Sci. 2018, 12, 98-105. [CrossRef]

47. Wang, S.; Zhang, C.; Chen, J. Utilization of Coal Fly Ash for the Production of Glass-ceramics With Unique Performances: A Brief Review. J. Mater. Sci. Technol. 2014, 30, 1208-1212. [CrossRef]

48. Sambandam, B.; Palanisami, E.; Abbugounder, R.; Prakhya, B.; Thiyagarajan, D. Characterizations of coal fly ash nanoparticles and induced in vitro toxicity in cell lines. J. Nanopart. Res. 2014, 16. [CrossRef]

49. Xu, G.; Shi, X. Characteristics and applications of fly ash as a sustainable construction material: A state-of-the-art review. Resour. Conserv. Recycl. 2018, 136, 95-109. [CrossRef]

50. Zanoletti, A.; Federici, S.; Borgese, L.; Bergese, P.; Ferroni, M.; Depero, L.E.; Bontempi, E. Embodied energy as key parameter for sustainable materials selection: The case of reusing coal fly ash for removing anionic surfactants. J. Clean. Prod. 2017, 141, 230-236. [CrossRef]

51. Rodella, N.; Bosio, A.; Zacco, A.; Borgese, L.; Pasquali, M.; Dalipi, R.; Depero, L.E.; Patel, V.; Bingham, P.A.; Bontempi, E. Arsenic stabilization in coal fly ash through the employment of waste materials. J. Environ. Chem. Eng. 2014, 2, 1352-1357. [CrossRef]

52. Chindaprasirt, P.; Jaturapitakkul, C.; Chalee, W.; Rattanasak, U. Comparative study on the characteristics of fly ash and bottom ash geopolymers. Waste Manag. 2009, 29, 539-543. [CrossRef]

53. Chen, Y.; Shah, N.; Huggins, F.E.; Huffman, G.P. Transmission Electron Microscopy Investigation of Ultrafine Coal Fly Ash Particles. Environ. Sci. Technol. 2005, 39, 1144-1151. [CrossRef]

54. Liu, R.P.; Guo, B.; Ren, A.; Bian, J.F. The chemical and oxidation characteristics of semi-dry flue gas desulfurization ash from a steel factory. Waste Manag. Res. 2010, 28, 865-871. [CrossRef]

55. Shenga, G.; Huanga, P.; Moua, Y.; Zhoub, C. Characteristics of fly ash from the dry flue gas desulfurization system for iron ore sintering plants. Environ. Technol. (UK) 2012, 33, 837-844. [CrossRef] [PubMed]

56. Bontempi, E.; Zacco, A.; Borgese, L.; Gianoncelli, A.; Ardesi, R.; Depero, L.E. A new method for municipal solid waste incinerator (MSWI) fly ash inertization, based on colloidal silica. J. Environ. Monit. 2010, 12, 2093-2099. [CrossRef] [PubMed]

57. Kost, D.A.; Bigham, J.M.; Stehouwer, R.C.; Beeghly, J.H.; Fowler, R.; Traina, S.J.; Wolfe, W.E.; Dick, W.A. Chemical and physical properties of dry flue gas desulfurization products. J. Environ. Qual. 2005, 34, 676-686. [CrossRef] [PubMed]

58. Liu, S.; Yang, H.; Zhang, Z.; Chen, J.; Chen, C.; Guo, T.; Cao, Y.; Jia, W. Emission characteristics of fine particles from wet flue gas desulfurization system using a cascade of double towers. Aerosol. Air Qual. Res. 2018, 18, 1901-1909. [CrossRef]

59. Li, X.; Chen, Q.; Zhou, Y.; Tyrer, M.; Yu, Y. Stabilization of heavy metals in MSWI fly ash using silica fume. Waste Manag. 2014, 34, 2494-2504. [CrossRef]

60. Assi, A.; Federici, S.; Bilo, F.; Zacco, A.; Depero, L.E.; Bontempi, E. Increased Sustainability of Carbon Dioxide Mineral Sequestration by a Technology Involving Fly Ash Stabilization. Materials 2019, 12, 2714. [CrossRef]

61. Bilo, F.; Lodolo, M.; Borgese, L.; Bosio, A.; Benassi, L.; Depero, L.E.; Bontempi, E. Evaluation of heavy metals contamination from environment to food matrix by TXRF: The case of rice and rice husk. J. Chem. 2015, 2015. [CrossRef]

62. Cement Concrete \& Aggregates Australia. Amorphous Silica Properties, Characterisation and Uses; Cement Concrete \& Aggregates Australia: Brisbane City, QLD, Australia, 2018.

63. Khater, H.M. Effect of silica fume on the characterization of the geopolymer materials. Int. J. Adv. Struct. Eng. 2013, 5. [CrossRef]

64. Siddique, R. Utilization of silica fume in concrete: Review of hardened properties. Resour. Conserv. Recycl. 2011, 55, 923-932. [CrossRef]

65. Zhu, W.; Zhou, Y.; Ma, W.; Li, M.; Yu, J.; Xie, K. Using silica fume as silica source for synthesizing spherical ordered mesoporous silica. Mater. Lett. 2013, 92, 129-131. [CrossRef]

66. Benassi, L.; Dalipi, R.; Consigli, V.; Pasquali, M.; Borgese, L.; Depero, L.E.; Clegg, F.; Bingham, P.A.; Bontempi, E. Integrated management of ash from industrial and domestic combustion: A new sustainable approach for reducing greenhouse gas emissions from energy conversion. Environ. Sci. Pollut. Res. 2017, 24, 14834-14846. [CrossRef] [PubMed] 
67. Jeong, S.G.; Jeon, J.; Cha, J.; Kim, J.; Kim, S. Preparation and evaluation of thermal enhanced silica fume by incorporating organic PCM, for application to concrete. Energy Build. 2013, 62, 190-195. [CrossRef]

68. Wang, Y.; Xia, T.D.; Zheng, H.; Feng, H.X. Stearic acid/silica fume composite as form-stable phase change material for thermal energy storage. Energy Build. 2011, 43, 2365-2370. [CrossRef]

69. Zanoletti, A.; Bilo, F.; Depero, L.E.; Zappa, D.; Bontempi, E. The first sustainable material designed for air particulate matter capture: An introduction to Azure Chemistry. J. Environ. Manag. 2018, 218, 355-362. [CrossRef]

70. Bilo, F.; Zanoletti, A.; Borgese, L.; Depero, L.E.; Bontempi, E. Chemical analysis of air particulate matter trapped by a porous material, synthesized from silica fume and sodium alginate. J. Nanomater. 2019, 2019. [CrossRef]

71. Zanoletti, A.; Bilo, F.; Federici, S.; Borgese, L.; Depero, L.E.; Ponti, J.; Valsesia, A.; La Spina, R.; Segata, M.; Montini, T.; et al. The first material made for air pollution control able to sequestrate fine and ultrafine air particulate matter. Sustain. Cities Soc. 2020, 53. [CrossRef]

72. Bontempi, E. A new approach for evaluating the sustainability of raw materials substitution based on embodied energy and the CO2 footprint. J. Clean. Prod. 2017, 162, 162-169. [CrossRef]

73. Della, V.P.; Kühn, I.; Hotza, D. Rice husk ash as an alternate source for active silica production. Mater. Lett. 2002, 57, 818-821. [CrossRef]

74. Mehtra, P.K.; Folliard, K.J. Rice Husk Ash-A Unique Supplementary Cementing Material: Durability Aspects. Spec. Publ. 1995, 154, 531-542. [CrossRef]

75. Ramezanianpour, A.A.; Mahdikhani, M.; Ahmadibeni, G. The effect of rice husk ash on mechanical properties and durability of sustainable concretes. Int. J. Civ. Eng. 2009, 7, 83-91.

76. Zain, M.F.M.; Islam, M.N.; Mahmud, F.; Jamil, M. Production of rice husk ash for use in concrete as a supplementary cementitious material. Constr. Build. Mater. 2011, 25, 798-805. [CrossRef]

77. Mehta, P.K. The Chemistry and Technology of Cement Made from Rice Husk Ash. In Proceedings of the UNIDO/ESCAP/RCTT Workshop on Rice Husk Ash Cements, Peshawar, Pakistan; Regional Centre for Technology Transfer: Bangalore, India, 1979.

78. Zhang, M.-H.; Malhotra, V.M. High-Performance Concrete Incorporating Rice Husk Ash as a Supplementary Cementing Material. ACI Mater. J. 1996, 93, 629-636.

79. Ramezanianpour, A.A.; Pourbeik, P.; Moodi, F.; Ahmadibeni, G. Sulfate resistance of concretes containing rice husk ash. In Proceedings of the 1st International Conference on Concrete Technology, Tabriz, Iran, 6-7 November 2009.

80. Saraswathy, V.; Song, H.W. Corrosion performance of rice husk ash blended concrete. Constr. Build. Mater. 2007, 21, 1779-1784. [CrossRef]

81. Akhtar, M.; Iqbal, S.; Kausar, A.; Bhanger, M.I.; Shaheen, M.A. An economically viable method for the removal of selected divalent metal ions from aqueous solutions using activated rice husk. Colloids Surfaces $B$ Biointerfaces 2010, 75, 149-155. [CrossRef] [PubMed]

82. Abo-El-Enein, S.A.; Eissa, M.A.; Diafullah, A.A.; Rizk, M.A.; Mohamed, F.M. Utilization of a low cost agro-residue for production of coagulant aids and their applications. J. Hazard. Mater. 2011, 186, 1200-1205. [CrossRef]

83. Conradt, R.; Pimkhaokham, P.; Leela-Adisorn, U. Nano-structured silica from rice husk. J. Non. Cryst. Solids 1992, 145, 75-79. [CrossRef]

84. Yao, Z.T.; Ji, X.S.; Sarker, P.K.; Tang, J.H.; Ge, L.Q.; Xia, M.S.; Xi, Y.Q. A comprehensive review on the applications of coal fly ash. Earth-Sci. Rev. 2015, 141, 105-121. [CrossRef]

85. Querol, X.; Moreno, N.; Umaa, J.C.; Alastuey, A.; Hernández, E.; López-Soler, A.; Plana, F. Synthesis of zeolites from coal fly ash: An overview. Int. J. Coal Geol. 2002, 50, 413-423. [CrossRef]

86. Moreno, N.; Querol, X.; Andrés, J.M.; Stanton, K.; Towler, M.; Nugteren, H.; Janssen-Jurkovicová, M.; Jones, R. Physico-chemical characteristics of European pulverized coal combustion fly ashes. Fuel 2005, 84, 1351-1363. [CrossRef]

87. Cho, H.; Ji, S.; Shin, H.; Jo, H. A Case Study of Environmental Policies and Guidelines for the Use of Coal Ash as Mine Reclamation Filler: Relevance for Needed South Korean Policy Updates. Sustainability 2019, 11, 3629. [CrossRef] 
88. Asl, S.M.H.; Javadian, H.; Khavarpour, M.; Belviso, C.; Taghavi, M.; Maghsudi, M. Porous adsorbents derived from coal fly ash as cost-effective and environmentally-friendly sources of aluminosilicate for sequestration of aqueous and gaseous pollutants: A review. J. Clean. Prod. 2019, 208, 1131-1147.

89. Erol, M.; Küçükbayrak, S.; Ersoy-Meriçboyu, A. Characterization of coal fly ash for possible utilization in glass production. Fuel 2007, 86, 706-714. [CrossRef]

90. Leroy, C.; Ferro, M.C.; Monteiro, R.C.C.; Fernandes, M.H.V. Production of glass-ceramics from coal ashes. J. Eur. Ceram. Soc. 2001, 21, 195-202. [CrossRef]

91. Palansooriya, K.N.; Shaheen, S.M.; Chen, S.S.; Tsang, D.C.W.; Hashimoto, Y.; Hou, D.; Bolan, N.S.; Rinklebe, J.; Ok, Y.S. Soil amendments for immobilization of potentially toxic elements in contaminated soils: A critical review. Environ. Int. 2020, 134, 105046. [CrossRef]

92. Baligar, V.C.; Clark, R.B.; Korcak, R.F.; Wright, R.J. Flue Gas Desulfurization Product Use on Agricultural Land. In Advances in Agronomy; Academic Press: Cambridge, MA, USA, 2011; Volume 111.

93. Sloan, J.J.; Dowdy, R.H.; Dolan, M.S.; Rehm, G.W. Plant and soil responses to field-applied flue gas desulfurization residue. Fuel 1999, 78, 169-174. [CrossRef]

94. Punshon, T.; Adriano, D.C.; Weber, J.T. Effect of flue gas desulfurization residue on plant establishment and soil and leachate quality. J. Environ. Qual. 2001, 30, 1071-1080. [CrossRef]

95. Wang, J.; Yang, P. Potential flue gas desulfurization gypsum utilization in agriculture: A comprehensive review. Renew. Sustain. Energy Rev. 2018, 82, 1969-1978. [CrossRef]

96. Caillahua, M.C.; Moura, F.J. Technical feasibility for use of FGD gypsum as an additive setting time retarder for Portland cement. J. Mater. Res. Technol. 2018, 7, 190-197. [CrossRef]

97. Yrjas, P.; Hupa, M.; Iisa, K. Pressurized Stabilization of Desulfurization Residues from Gasification Processes. Energy Fuels 1996, 10, 1189-1195. [CrossRef]

98. Cheng, J.; Zhou, J.H.; Liu, J.Z.; Zhou, Z.J.; Cao, X.Y.; Cen, K.F. Crystal compositions of self-desulfurization residues from a pulverized coal fired boiler. Ranliao Huaxue Xuebao/J. Fuel Chem. Technol. 2005, 33, $38-42$.

99. Da-gen, S.; Kang, C.; Xiao, H.; Cheng, H.; Hui-min, L. On the Application of Desulphurization Residues in the Cement Industry. Multipurp. Util. Miner. Resour 2006, 5. Available online: http://en.cnki.com.cn/Article_ en/CJFDTotal-KCZL200605010.htm (accessed on 6 May 2020).

100. Chen, Z.; Wu, S.; Li, F.; Chen, J.; Qin, Z.; Pang, L. Recycling of Flue Gas Desulfurization residues in gneiss based hot mix asphalt: Materials characterization and performances evaluation. Constr. Build. Mater. 2014, 73, 137-144. [CrossRef]

101. Fahimi, A.; Bilo, F.; Assi, A.; Dalipi, R.; Federici, S.; Guedes, A.; Valentim, B.; Olgun, H.; Ye, G.; Bialecka, B.; et al. Poultry litter ash characterization and recovery. Waste Manag. 2020.

102. Chou, M.-I.M.; Bruinius, J.A.; Benig, V.; Chou, S.-F.J.; Carty, R.H. Producing Ammonium Sulfate from Flue Gas Desulfurization By-Products. Energy Sour. 2005, 27, 1061-1071. [CrossRef]

103. Besco, S.; Bosio, A.; Brisotto, M.; Depero, L.E.; Lorenzetti, A.; Bontempi, E.; Bonora, R.; Modesti, M. Structural and mechanical characterization of sustainable composites based on recycled and stabilized fly ash. Materials 2014, 7, 5920-5933. [CrossRef]

104. Assi, A.; Bilo, F.; Zanoletti, A.; Ducoli, S.; Ramorino, G.; Gobetti, A.; Zacco, A.; Federici, S.; Depero, L.E.; Bontempi, E. A Circular Economy Virtuous Example-Use of a Stabilized Waste Material Instead of Calcite to Produce Sustainable Composites. Appl. Sci. 2020, 10, 754. [CrossRef]

105. Paliwal, M.K.; Chaturvedi, S.K. An Experimental Investigation of Tensile Strength of Glass Composite Materials with Calcium Carbonate (CaCO 3) Filler. Int. J. Emerg. Trends Eng. Dev. 2012, 2, 303-309.

106. Reddy, S.P.; Chandra, P.V.; Rao, S.; Reddy, A.C.; Parmeswari, G. Tensile and Flexural Strength of Glass Fiber Epoxy Composite. In Proceedings of the International Conference on Advanced Materials and manufacturing Technologies (AMMT), JNTUH CEH, India, 18-20 December 2014.

107. Srivastava, V.K.; Shembekar, P.S. Tensile and fracture properties of epoxy resin filled with flyash particles. J. Mater. Sci. 1990, 25, 3513-3516. [CrossRef]

108. Maiti, S.N.; Mahapatro, P.K. Mechanical properties of i-PP/CaCO3 composites. J. Appl. Polym. Sci. 1991, 42, 3101-3110. [CrossRef]

109. Satheesh Raja, R.; Manisekar, K.; Manikandan, V. Study on mechanical properties of fly ash impregnated glass fiber reinforced polymer composites using mixture design analysis. Mater. Des. 2014, 55, 499-508. [CrossRef] 
110. Gummadi, J.; Kumar, G.V.; Rajesh, G. Evaluation of Flexural Properties of Fly Ash Filled Polypropylene Composites. Int. J. Mod. Eng. Res. 2012, 2, 2584-2590.

111. Sengupta, S.; Pal, K.; Ray, D.; Mukhopadhyay, A. Furfuryl palmitate coated fly ash used as filler in recycled polypropylene matrix composites. Compos. Part B Eng. 2011, 42, 1834-1839. [CrossRef]

112. Yang, K.; Yang, Q.; Li, G.; Sun, Y.; Feng, D. Mechanical properties and morphologies of polypropylene with different sizes of calcium carbonate particles. Polym. Compos. 2006, 27, 443-450. [CrossRef]

113. Gupta, N.; Brar, B.S.; Woldesenbet, E. Effect of filler addition on the compressive and impact properties of glass fibre reinforced epoxy. Bull. Mater. Sci. 2001, 24, 219-223. [CrossRef]

114. Maiti, S.N.; Sharma, K.K. Studies on polypropylene composites filled with talc particles—Part I Mechanical properties. J. Mater. Sci. 1992, 27, 4605-4613. [CrossRef]

115. Švehlová, V.; Polouček, E. About the influence of filler particle size on toughness of filled polypropylene. Angew. Makromol. Chem. 1987, 153, 197-200. [CrossRef]

(C) 2020 by the authors. Licensee MDPI, Basel, Switzerland. This article is an open access article distributed under the terms and conditions of the Creative Commons Attribution (CC BY) license (http://creativecommons.org/licenses/by/4.0/). 